\title{
СОЦИАЛЬНАЯ ПСИХИАТРИЯ
}

\section{УДК 616.89+167/168-022.3:616.89.008.441.13:613.83:330.564.2}

Для цитирования: Артемьев И.А. Преемственность как научно-концептуальный футурологический подход к эпистемологии социальной психиатрии. Сибирский вестник психиатрии и наркологии. 2021; 2 (111): 73-81. https://doi.org/10.26617/1810-3111-2021-2(111)-73-81

\section{Преемственность как научно-концептуальный футурологический подход к эпистемологии социальной психиатрии}

\section{Артемьев И.А.}

НИИ психического здоровья, Томский нацчиональный исследовательский медицинский ичентр

Российской академии наук

Россия, 634014, Томск, ул. Алеутская, 4

\section{PЕЗЮME}

В статье рассматриваются поисковые стратегические направления, которые сформировались в течение последних двух десятилетий в рамках развития многоуровневой преемственности в изучении социальных детерминант психического здоровья определенных социальных групп и общества в целом. В качестве основных были избраны такие универсальные и потенциально значимые показатели, которые оказывают брутальное влияние на полный комплекс социального развития всего населения вне зависимости от территориального (регионального, локального и др.) расположения, этнических и культуральных особенностей, материального благосостояния и социального статуса населения, а также прочих внешних и внутренних факторов, воздействующих напрямую и опосредованно. Изучалась взаимосвязь основных социально-демографических параметров, являющихся общими для всей популяции рассматриваемого региона, таких как миграция населения, безработица и распространенность психических расстройств, соотношение показателей бедности и денежных доходов населения с уровнем зарегистрированного алкоголизма и наркоманий в регионе.

Ключевые слова: социальная психиатрия, нозологическое и синдромологическое направление, социометрические методы, охрана психического здоровья, алкоголизм, миграция, безработица, бедность.

\section{ВВЕДЕНИЕ}

Футурологический метод прогноза предполагаемых перспектив социальных изменений - важный этап развития психиатрии как клинической дисциплины с её многочисленными взаимосвязями с широким спектром окружающей действительности, в том числе с учетом социальных аспектов. Этот метод во многом способствовал признанию Комитетом ВОЗ в 1958 г. отдельной дисциплины - социальной психиатрии как самостоятельной науковедческой единицы, имеющей свои научные границы, объём знаний и перспективы дальнейшего развития.

В конце 1990-х гг. В.Я. Семке сформулировал главные постулаты, призванные в ближайшее время определять аналитико-исторические исследования в этой новой области психиатрии [1]. Из числа разнообразных вопросов, составляющих предмет, задачи и содержание социальной психиатрии, автором вычленяются: 1) эпистемологический (науковедческий) аспект, терминологические дефиниции; 2) теоретико-методологические и системно-структурные основы, среди которых вычленяются эпидемиологический, этиопатогенетический и экологический подходы; 3) кросскультуральная психиатрия (транскультуральная, культуральная и этнопсихиатия), культуральный подход к клинической диагностике и терапии; 4) модели взаимодействия в реабилитационнопревентивной сфере, лечебная и социальнотрудовая маршрутизация.

Нами приводится краткое описание основополагающих направлений, которые сформировались в рамках преемственности и развития предложенной автором доктрины в течение последних двух десятилетий после публикации данной статьи.

В качестве определяющих категорий были избраны значимые детерминирующие факторы, оказывающие брутальное влияние на целостный комплекс социального развития всего населения вне зависимости от территориального (регионального, локального и др.) расположения, этнических и культуральных особенностей, материального благосостояния и социального статуса населения, а также прочих внешних и внутренних 
факторов, воздействующих напрямую и опосредованно.

\section{ЦЕЛЬ ИССЛЕДОВАНИЯ}

Изучить взаимосвязь социально-демографических параметров, являющихся общими для всей популяции рассматриваемого региона, таких как миграция населения, безработица и распространенность психических расстройств, а также соотношение бедности и денежных доходов населения с уровнем зарегистрированного алкоголизма и наркоманий в регионе [2].

Мы склонны считать, что изложенные материалы конкретизируют положения упомянутой работы [1] как в части эпистемологической, этнокультуральной, так и в других аспектах, декларируемых автором. Фактологические данные были опубликованы ранее [3, 4, 5, 6, 7], поэтому нами излагается резолютивная часть исследований.

\section{МАТЕРИАЛЫ И МЕТОДЫ}

Показатели психического здоровья населения определялись и подвергнуты сравнительному анализу у жителей трех территориальных субъектов: 1) интенсивно осваиваемый регион Тюменского Севера, Уральский ФО (Сургут); 2) традиционный регион юго-восточной части Сибири, Сибирский ФО (Кызыл); 3) традиционный регион Дальневосточного округа (ПетропавловскКамчатский). Объем выборки: исследованием персонально охвачено около 3500 больных психическими расстройствами, проживающих в трёх городах - Сургуте, Петропавловске-Камчатском и Кызыле. По европейским масштабам процессы территориального перемещения в широтном и меридиональном векторах соответствуют траекториям: Лондон - Нью-Йорк, Лондон - Афины.

\section{РЕЗУЛЬТАТЫ И ОБСУЖДЕНИЕ}

Роль миграции в формировании контингентов больных психическими расстройствами

Термин «миграция населения» включает несколько её видов: внутренняя, внешняя, эмиграция на постоянное место жительства, временная, долгосрочная, маятниковая, эпизодическая приграничная, обратная, кочевничество, паломничество, а также беженцы и вынужденные переселенцы. Миграции имманентны специфические, определенные функции (по направлению или времени). Миграция выступает как источник рынка труда, а мигранты - как потенциальный трудовой резерв. Миграция выполняет функцию перераспределения рабочей силы на рынке труда, т.е. миграционные потоки определяются потребностью в трудовых ресурсах определенных территорий. Медицинская парадигма миграции населения представляет собой перемещение, перераспределение здоровья. В этом контексте миграция населения определяется как направленный поток здоровья, за счет которого и происходит освоение новых территориальных пространств и развитие уже сложившихся производств $[8,9,10]$.

Оказалось, что миграция благодаря своей селективной функции, заключающейся в изменении качественного состава населения, оказывает неоднозначное влияние на распространенность психических заболеваний и алкоголизма в популяциях мест иммиграции.

На примере динамично развивающегося города Тюменского Севера (Сургута), где население за рассматриваемый период возросло в 1,5 раза, и одного из городов Южной Сибири (Кызыла), в котором население за тот же период увеличилось на 10\%, нами обнаружено, что вновь формирующаяся северная городская популяция имеет более низкие частоты встречаемости психических расстройств, нежели южно-сибирская. Уровень психической патологии в ней превосходит аналогичные значения для северной популяции в 3,8 раза, по психозам - в 4,5 раза, по непсихотическим психическим расстройствам - в 3,4 раза. Вместе с тем в обоих случаях распространенность больных психическими заболеваниями жестко связана со среднегодовой численностью населения. Следовательно, параллельно с формированием населения северного города происходит увеличение количества больных в нём, в отличие от стационарной городской популяции, где эта величина остается стабильной. Однако механический прирост населения последнего неоднозначно связан с уровнем больных психозами и непсихотическими расстройствами, эта обусловленность имеет разнонаправленные значения. Следовательно, иммигрирующее население привносит в популяцию южно-сибирского города больных с психотическими формами заболеваний и умственной отсталостью, а больные непсихотическими психическими заболеваниями (неврозами и психопатиями) в ближайшие сроки наблюдения не становятся объектом внимания специалистов психиатрической службы. Для северного города миграционный прирост и распространенность психических заболеваний находятся в противоположных фазах: первый затихает, второй, напротив, прогрессирует. Таким образом, взаимосвязь миграционного прироста населения с уровнем распространенности психических заболеваний неоднозначна не только для различных городских популяций, но и для частоты встречаемости психотических и непсихотических расстройств.

Интенсивность миграции сама по себе не является обстоятельством, приводящим к «самоочищению» населения, «вымыванию» лиц, нуждающихся в оказании психиатрической или наркологической помощи. Так, в район интенсивного промышленного освоения нефтегазовых месторождений (Сургут) прибыло здоровыми 93\% 
от общего числа больных шизофренией, а в традиционную городскую модель (Кызыл) - 72\%.

Динамика миграционного прироста однозначно (отрицательно) связана с показателями распространенности алкоголизма: при затухающем механическом приросте они увеличиваются и, наоборот, относительная стабильность указанного прироста не ведет к возрастанию частоты алкоголизма. Таким образом, миграционные потоки в районы нового промышленного освоения и интеграционного социально-экономического развития территорий Сибири способствуют минимизации частотного уровня распространённости психических заболеваний и алкоголизма. В то время как на примере традиционных городских моделей такой взаимосвязи не обнаружено. Прибывающее население способствует «оздоровлению» мест вселения, но в дальнейшем происходит «накопление» психической патологии и выравнивание с уровнем традиционно устоявшихся регионов. Следовательно, перемещение населения следует рассматривать, прежде всего, как миграцию ингредиента здоровья на рынке труда. В этом отношении Сибирь находится в чрезвычайно невыгодной ситуации из-за неблагоприятных природно-климатических и социальных условий среды.

Миграция людей, даже несмотря на наличие у них психических расстройств, явление глобально-повсеместное во всем мире и в России в частности, не взирая на декретированные ограничения для этой категории переселенцев, принятые в Сургуте. Однако анализ динамики их количества в общей численности переселенцев в объектных городах нашего собственного исследования позволил установить, что эта величина определяется не столько особенностями масштабных миграционных процессов, сколько соотношением внутриобластных и межрегиональных (межтерриториальных) перемещений.

Этническая среда и психические расстройства при миграции

На примере Тувы нами рассмотрены некоторые особенности миграции, связанные с этнической принадлежностью мигрантов. Проанализированы данные о больных русской и тувинской национальностей, образующих популяции психически больных в Кызыле. Подобные этнопсихиатрические сравнения имеют не только академический интерес, но и результаты этих исследований сказываются на политике охраны психического здоровья населения. Проведена сравнительная оценка распространенности и клиниконозологической структуры психических расстройств у русского и тувинского населения в Республике Тыва, где сосредоточено 98\% от всей мировой популяции тувинцев. На примере русских и тувинцев - жителей Кызыла прослеже- ны этнические особенности формирования контингентов психически больных мигрантов и аборигенов-тувинцев. Оказалось, что среди мигрантов и аборигенов русские и тувинцы представлены в равных пропорциях: мигранты-русские $78 \%$ и мигранты-тувинцы - 79\% от общего количества состоящих на учете (соответственно $\mathrm{n}=658$

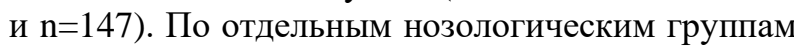
не выявлено существенных отличий. Не установлено этнических различий как среди аборигенов, так и мигрантов русской и тувинской национальностей в исторически сложившейся популяции психически больных Кызыла. Более того, выявлено поразительное сходство в пропорциях как местных уроженцев, так и приезжего населения.

Таким образом, этнические различия при миграции тувинцев и русских не сказываются на процессе формирования контингентов психически больных как русских, так и тувинцев.

Доля непсихотических расстройств, включая неврозы, психопатии и расстройства непсихотического характера на почве органического поражения головного мозга, в общей структуре нервно-психической патологии в тувинской субпопуляции была статистически значимо $(\mathrm{p}<0,05)$ ниже $(5,8 \%)$, чем в русскоязычной $(15,9 \%)$.

У мигрантов русской национальности возникает большое число различных психотических расстройств. Эта закономерность сохраняется вне зависимости от типа миграции. Однако при переезде внутри республики (внутриобластная миграция) такие различия не достигают достоверного уровня $(17,9 \pm 3,9 \%$ - у тувинцев и $22,8 \pm 3,4 \%-$ у русских; p>0,05). Вместе с тем при межобластной миграции эти различия статистически значимы $(28,7 \pm 03,5 \% ; \mathrm{p}<0,05)$.

Вероятно, коренным жителям Тувы присуща более высокая терпимость к психическим расстройствам у пожилых людей. С другой стороны, требования к их поведению со стороны родственников таково, что позволяет им не прибегать к помощи психиатров. В то же время и русские, проживающие Туве, моделируют аналогичный стиль отношения к этой категории больных, «копируя» его у местных жителей, в отличие от представителей русской национальности, мигрировавших из других территорий и дающих более высокий удельный вес психических расстройств.

Следовательно, больший удельный вес психических расстройств среди мигрантов-русских невозможно объяснить только этническими особенностями. Вероятно, это результат социокультурной толерантности тувинского социума к психически больным. Доказательством этому может служить противоположное процентное соотношение больных шизофренией: русские $34,9 \pm 2,3 \%$, тувинцы $-49,4 \pm 5,3 \%(p<0,05)$. Хотя 
расстройства других нозологических групп представлены в одинаковых пропорциях.

Следовательно, различия между мигрантами русскими и тувинцами касаются только больных психотическими расстройствами. В то время как непсихотические расстройства у представителей двух рассматриваемых этносов встречаются примерно с одинаковой частотой.

Психиатры в настоящее время работают во всё более многокультуральном мире, сформированном миграцией людей различных культуральных, расовых и этнических групп. Оказание медицинской помощи непреложно находится под влиянием требований людей самых разных культур. Поэтому важно, чтобы межкультуральные различия были верно оценены и поняты, чтобы прийти к правильному диагностическому мнению и выбору реабилитационных программ $[11,12,13]$

\section{Психическое здоровье безработных}

Социально-экономические изменения, происходящие в России в настоящее время, побуждают исследователей подойти к изучению состояния психического здоровья безработных, а также факторов, влияющих на формирование нервнопсихических расстройств у этого контингента лиц, форм и методов их реабилитации [14].

Безработицу традиционно рассматривают как трудную жизненную ситуацию, требующую от индивида действий и условий, находящихся на границе его адаптивных возможностей или даже превосходящих имеющиеся у него фактические резервы [15]. Вместе с тем оценка безработицы как психосоциального стрессового фактора, приводящего к формированию широчайшего спектра психических расстройств, тем не менее представляется чрезвычайно весомой и убедительной. Так, большинство исследователей оценивают вынужденную незанятость как один из значимых факторов, определяющих становление, развитие и продолжительность психической патологии. Безработица в МКБ-10 рассматривается как социальноэкономический и психологический фактор, представляющий потенциальную опасность для здоровья (Z.56.0 и Z.56.2).

В настоящее время опубликованы достаточно многочисленные данные, обоснованно свидетельствующие о негативном влиянии потери работы и вынужденной незанятости на психическое здоровье индивида и рассматривающиеся как последствие стресса. В частности подчеркивается прямая связь между уровнем общей заболеваемости, показателями смертности и безработицей [16]. Во многих исследованиях выявлены сильные корреляционные связи с высоким уровнем значимости между показателями регистрируемой безработицы и числом самоубийств, заболеваемостью алкоголизмом и алкогольными психозами
[17], количеством совершенных преступлений [18].

Собственная выборка исследования - 102 безработных трудоспособного возраста (35-55 лет). Использовались скрининг-методики (ПОСПЗ) для выявления внутриличностной дезинтеграции, соотношения «ценности» и «доступности» в различных жизненных сферах.

Полученные данные позволяют рассматривать безработицу как фактор риска формирования непсихотических психических расстройств, если выполняются следующие условия: 1) ситуация имеет объективно вынужденный, неконтролируемый личностью характер; 2) возраст безработного более 45 лет; 3) ситуация незанятости субъективно оценивается как «проблемная», отражая фрустрацию неудовлетворенных значимых потребностей личности; 4) отсутствуют источники финансовой и эмоциональной поддержки.

Психические расстройства, развившиеся в ответ на утрату работы, полиморфны в своих клинических проявлениях и различны по степени выраженности. Наиболее характерными в данном случае являются депрессивные, тревожные, соматоформные, поведенческие расстройства, алкоголизм, злоупотребление другими психоактивными веществами, высокий суицидальный риск $[19,20$, 21, 22, 23].

Особый интерес представляет конщеепция социально-стрессовых расстройств, постулирующая развитие состояний психической дезадаптации у безработных, в частности в виде формирования донозологических состояний.

Собственную выборку составили 186 безработных, состоящих на учете в центре занятости населения (Томск). Скрининг-обследование позволило выделить высокую долю безработных с донозологическими формами непсихотических психических расстройств - 29,3\%. Среди обследованных женщины преобладали $(87,4 \%)$ по сравнению с мужчинами (12,6\%).

Таким образом, клинически донозологические формы ПНПР были представлены астеническими и аффективными симптомокомплексами. Донозологические невротические нарушения у безработных возникают на фоне эмоционального переживания, связанного с индивидуально значимыми психотравмирующими обстоятельствами, характеризующими трудовую незанятость, когда имеют место снижение уровня материального благосостояния, неудовлетворение физических и социальных потребностей, неопределенность будущего, социальная депривация. Выделяются два направления, по которым развиваются предболезненные невротические нарушения (донозологические) у безработных: 1) с преобладанием астенических проявлений, имеющих характерную 
сенсорную гипопатическую и анергическую окраску, 2) с обострением личностных особенностей.

Основной причиной ухудшения здоровья треть $(34,8 \%)$ безработных считают хронический стресс, в группе работающих - 3,2\% $(\mathrm{p}<0,05)$. С течением времени большинство $(89,7 \%)$ безработных отмечают изменение состояния своего здоровья в худшую сторону. При проведении гендерного сравнения портрета психического здоровья установлено, что женщины в 1,3 раза чаще подвержены стрессу, в 1,6 раза чаще - депрессивным, в 1,3 раза чаще - тревожным расстройствам, чем мужчины. Качество жизни безработными оценивается значительно ниже, чем среди занятого населения, что в большей степени обусловлено нарушением психоэмоциональных возможностей. С увеличением периода трудовой незанятости отмечается рост уровня стресса, симптомов тревоги и депрессии, причём максимум нарушений наблюдается после 6 месяцев безработицы. Через 12 месяцев незанятости подверженность безработных депрессивным расстройствам резко увеличилась в 10 раз, подверженность тревожным расстройствам - в 7,2 раза, предрасположенность к стрессу - в 1,5 раза [82].

Подавляющее большинство авторов, изучавших психогенное влияние безработицы, указывают на высокую распространенность среди лиц, утративших работу, психогенно обусловленных депрессивных и тревожных расстройств.

Субклинически выраженная депрессия наблюдалась у 2,9 $\pm 0,8 \%$ респондентов, клинически выраженные симптомы депрессии - у 2,2 $\pm 0,7 \%$. В целом нарушения психического здоровья депрессивного спектра в категории безработных отмечались в 28,5 $\pm 2,1 \%$ случаев, тогда как в группе работающих значительно реже - 5,1 1,1\%. При изучении выраженности симптомов тревоги установлено, что у $34,1 \pm 2,2 \%$ безработных выявлена субклинически выраженная тревога, у 10,2士1,4\% - клинически выраженная тревога. В группе работающих субклинически выраженная и клинически выраженная тревога наблюдалась с более редкой частотой $(7,0 \pm 1,2 \%$ и $1,7 \pm 0,6 \%)$. Доля зарегистрированных симптомов тревоги у безработных превышала таковую в группе работающих $(44,3 \pm 2,4 \%$ против $8,7 \pm 1,3 \%)$. Из этого можно сделать вывод, что среди незанятого населения симптомы тревоги встречаются в 5 раз чаще, чем среди работающего населения.

Анализ влияния отечественной безработицы на здоровье населения за 10-летний период показал, что безработица не оказывает влияния на заболеваемость населения (все болезни), отсутствует связь между безработицей, алкоголизмом и алкогольными психозами, не влияет она и на число выявленных совершенных преступлений, в том числе гражданами без определенных доходов, так же как и на масштабы самоубийств.

Типичный социально-психологический портрет российского безработного представлен следующим образом: низкий уровень социальной активности, уступчивость, конформность, пессимистичность и осторожность в поведении, подозрительность, недоверчивость и скептицизм, высокий уровень тревоги и недовольства. Таким образом, существуют несколько методологических подходов, в рамках которых предпринимаются попытки объяснить влияние вынужденной трудовой незанятости на психическое здоровье. Не умаляя значимости каждого из них, в то же время необходимо изучение конкретных факторов, характеризующих взаимосвязь безработицы и психического здоровья.

Выводы. На индивидуальном уровне безработицу можно определить как стрессовое событие в жизни человека. Между безработицей и здоровьем существует обратно пропорциональная зависимость. Как правило, влияние безработицы на здоровье рассматривается в контексте социального стресса. Безработица оказывает идентичное воздействие как на тех, кто потерял работу, так и на тех, кто её еще имеет. Литературные данные, посвященные анализу факторов, влияющих на психическое здоровье безработных, можно разделить на социально-демографические, социальнопсихологические и факторы, отражающие специфические особенности собственно ситуации вынужденной незанятости. Выделен характерный для безработных психопатологический симптомокомплекс с тягостным чувством неполноценности и депрессией. В ходе дальнейшего анализа у безработных установлено формирование выраженных физиологических изменений.

\section{Бедность и наркотизм}

В документе «Ликвидация разрыва» ВО3 декларирует: «Самый беспощадный убийца мира и главная причина страдания на Земле - это чрезмерная бедность». Это заявление подчеркивает значимость бедности как фактора, неблагоприятно влияющего на здоровье. Бедность - это явление, присущее всем без исключения общественным системам. Как многомерное явление, по сути, бедность может вызывать отчуждение и напряжение, но особую озабоченность вызывает её прямое и косвенное влияние на развитие психических расстройств $[24,25,26]$.

Проведено популяционно-статистическое исследование бедности с определением её взаимосвязи с уровнем учтенной болезненности наркоманиями и алкоголизмом в отдельно взятом субъекте РФ - Томской области (ТО). Выявлены различия по распространенности алкоголизма и 
наркоманий в отдельных муниципальных образованиях области в зависимости от показателей уровня бедности.

Единых методологических подходов к определению понятия «бедность» не существует (Стратегия сокращения бедности. Томск, 2005). На муниципальном уровне показатели бедности не рассчитываются Росстатом, но в Томской области сотрудниками Института экономики и менеджмента и областного Департамента социальной защиты проведено системное исследование, при выполнении которого использовались интенсивные показатели зарегистрированных больных (F10.2-9-F11-19) в соответствии с основными показателями деятельности наркологической службы в Российской Федерации [2]. Кроме того, применялись показатели бедности, денежных доходов в целом по отдельным территориальноадминистративным территориям региона.

Доходы населения и распространенность наркоманий

По значению индекса доходов населения для благополучных муниципальных образований (І группа) характерен самый высокий уровень зарегистрированной болезненности наркоманиями (соответственно 106,9; 61,8; 55,8 на 10 тыс. населения). Относительно благополучные районы по тому же показателю имеют более низкий уровень зарегистрированной болезненности (24,753,3). В относительно неблагополучных и неблагополучных районах рассматриваемая зависимость воспринимается не так очевидно, однако выявленные тенденции протекают синхронно.

Следовательно, достоверными данными о наличии взаимосвязи между первичным выявлением больных наркоманиями в благополучных и неблагополучных муниципальных образованиях по доходам населения мы не располагаем. Это может лишь косвенно подтверждать, что заболеваемость (первичное выявление) наркоманиями выше в муниципальных образованиях с более высоким индексом доходов населения. Можно допустить, что заболеваемость и болезненность наркоманиями ассоциированы с более высокими показателями доходов населения в муниципальных образованиях. Данное предположение применимо даже в том случае, когда значения коэффициента корреляции показателя заболеваемости и индекса доходов не достигают принятого нами $80 \%$ уровня достоверности.

Таким образом, выявленный отрицательный характер связи бедности населения с количеством зарегистрированных больных наркоманией свидетельствует о том, что по мере увеличения доли населения с доходами, превышающими прожиточный минимум, по всей вероятности, будет возрастать и количество больных наркоманией.
С другой стороны, большая величина бедности ассоциируется с меньшей численностью больных наркоманией.

Таким образом, интерпретация коэффициента корреляции $(\mathrm{r}=-28, \mathrm{p}=0,22)$ иллюстрируется фактическими данными по конкретным территориям: при более высоком материальном благополучии учтенная распространенность наркоманий выше. В неблагополучных по показателю бедности муниципальных образованиях количество больных наркоманиями ниже. Следовательно, прогностически следует ожидать, что прогрессирующее изменение контингентов больных наркоманиями будет происходить по всей территории области по мере уменьшения бедности ее населения.

Доходы населения и распространенность алкоголизма

Показатели заболеваемости и распространенности алкоголизма в муниципальных образованиях Томской области не связаны с индексом доходов населения, который включает, наряду с перечисленными выше величинами, и размер средней заработной платы. Следовательно, уровень алкоголизма в отдельных муниципальных образованиях не зависит от материального благополучия, обеспеченного заработной платой, а также других параметров рассматриваемого индекса. Т.е. изучение взаимосвязи распространенности наркоманий и алкоголизма с индексом доходов населения в городах и районах ТО показало статистически значимые различия: если количество больных наркоманиями на 10 тыс. населения коррелирует с доходами населения (включая заработную плату), то при алкоголизме такая связь отсутствует.

Следовательно, в муниципальных образованиях с более высокими доходами имеется больше больных наркоманиями (на 10 тыс. населения), нежели в муниципальных образованиях с низкими доходами населения. Т.е. благополучные по доходам районы, по сути, являются «неблагополучными» по уровню распространенности наркоманий, при этом взаимосвязь алкоголизма (на 10 тыс. населения) с доходами не прослеживается. Вероятно, удовлетворение спроса на алкоголь происходит за счет других источников доходов. В то же время спрос на наркотики удовлетворяется за счет доходов части населения, не подверженной этой аддикции (родители, родственники), что может свидетельствовать о большем «социальном паразитизме» наркозависимых.

Следовательно, взаимосвязь уровня бедности и прожиточного минимума с частотой распространенности алкоголизма и наркоманий различна. Если распространенность алкоголизма умеренно и положительно взаимосвязана с величиной прожиточного минимума и не имеет связи с бедностью населения, то распространенность 
наркоманий отрицательно коррелирует с бедностью при отсутствии связи с прожиточным минимумом.

Поскольку прожиточный минимум - директивная константа, отражающая уровень доходов населения в определенный период, то его увеличение синхронизируется с ростом доли больных алкоголизмом в населении, но этот процесс не затрагивает величину больных наркоманиями. Однако уровень бедности не влияет на показатели распространенности алкоголизма, тогда как тенденция к её сокращению может привести к росту численности больных наркоманиями.

За рассматриваемый 20-летний период удалось доказательно обосновать, что эпидемиологическую ситуацию отдельных административных единиц Томска и Томской области нужно рассматривать не только по данным государственной статистики, но и с учетом динамики социальнодемографической ситуации, присущей конкретной территории. Только на основе тематикоаналитического обобщения всего объема совокупных данных можно строить стратегию компетентного оказания психиатрической и наркологической помощи, а также стационарного и амбулаторного обслуживания контингента психически больных.

\section{КОНФЛИКТ ИНТЕРЕСОВ}

Автор заявляет об отсутствии явных и потенциальных конфликтов интересов в связи с публикацией данной статьи.

\section{ИСТОЧНИК ФИНАНСИРОВАНИЯ}

Работа выполнена по теме основного плана НИР «Комплексное исследование клиникопсихопатологических закономерностей и патобиологических механизмов формирования и прогредиентности социально значимых психических и поведенческих расстройств с разработкой инновационных методов ранней диагностики, персонализированных стратегий терапии и профилактики» (№ рег. АААА-А19-119020690013-2).

\section{СООТВЕТСТВИЕ ПРИНЦИПАМ ЭТИКИ}

Работа соответствует этическим стандартам Хельсинской декларации ВМА и одобрена этическим комитетом НИИ психического здоровья Томского НИМЦ (протокол № 127 от 09.12.2019 г.).

\section{ЛИТЕРАТУРА/REFERENCES}

1. Семке В.Я. Социальная психиатрия: путь в новое тысячелетие. Сибирский медицинский журнал. 1999. № 1-2. C. 5-15 . Semke VYa. Social Psychiatry: A Path to the New Millennium. Siberian Medical Journal. 1999;1-2:5-15 (in Russian).

2. Российский статистический ежегодник 2018: Статистический сборник. М. : Росстат, 2018. 694 c. Russian Statistical Yearbook 2018: Statistical Book. Moscow: Rosstat, 2018:694 (in Russian).

3. Артемьев И.А. Миграция населения Сибири и Дальнего Востока и ее взаимосвязь с некоторы- ми неинфекционными заболеваниями. В книге: Атлас онкологической заболеваемости населения Сибири и Дальнего Востока / Л.В. Писарева, Б.Н. Зырянов, Н.В. Васильев, А.И. Потапов, А.П. Бояркина. Томск, 2012. С. 135-146. Artemiev IA. Migration of the population of Siberia and the Far East and its relationship with some noncommunicable diseases. In the book: Atlas of oncological morbidity of the population of Siberia and the Far East / LV Pisareva, BN Zyryanov, N.V. Vasiliev, A.I. Potapov, A.P. Boyarkina. Tomsk, 2012:135-146 (in Russian).

4. Артемьев И.А., Кошелева Л.Н., Смердов С.А., Чемакин Ю.А. Демографические процессы и психическое здоровье жителей города Сургута. Сургут; Томск, 1998. 128 с. Artemiev IA, Kosheleva LN, Smerdov SA, Chemakin YuA. Demographic processes and mental health of the inhabitants of the city of Surgut. Surgut; Tomsk, 1998:128 (in Russian).

5. Гычев А.В., Артемьев И.А., Семке В.Я. Безработица в России и психическое здоровье. Томск, 2010. 160 c. Gychev AV, Artemiev IA, Semke VYa. Unemployment in Russia and mental health. Tomsk, 2010:160 (in Russia).

6. Артемьев И.А., Бохан Н.А. Миграция населения и психические расстройства. Томск : ООО «Интегральный переплет», 2020. 106 c. Artemyev IA, Bokhan NA. Migration of the Population and Mental Disorders. Tomsk : Printing House Integrated Casework, 2020:106. (in Russian).

7. Артемьев И.А., Бохан Н.А., Мандель А.И., Галажинский Э.В. Распространенность гашишизма в Сибири в этническом и территориальном аспектах. Журнал неврологии и психиатрии им. С.С. Корсакова. 2014. Т. 114, № 9. С. 61-65. Artemiev IA, Bokhan NA, Mandel AI, Galazhinsky EV. The prevalence of hashishism in Siberia in ethnic and territorial aspects. S.S. Korsakov Journal of Neurology and Psychiatry. 2014;114(9):61-65 (in Russian).

8. Семке В.Я. Производственная миграция и психическое здоровье. Сибирский вестник психиатрии инаркологии. 2012. № 2 (71). С. 5-6. Semke VYa. Work migration and mental health. Siberian Herald of Psychiatry and Addiction Psychiatry. 2012;2(71):5-6 (in Russian).

9. Иванова М.В. Психическое здоровье мигрантов: автореферат дис. ... к.м.н. Томск, 2007. 27 с. Ivanova MV. Mental health of migrants: PhD thesis. Tomsk, 2007:27 (in Russian).

10. Рыбаковский Л.Л. Миграция населения: прогнозы, факторы, политика. М. : Изд-во Наука, 1987. 199 c. Rybakovsky LL. Population migration: forecasts, factors, politics. Moscow: Publishing House Nauka, 1987:199 (in Russian).

11. Bhugra D, Gupta S, Bhui K, Craig T, Dogra N, Ingleby JD, Kirkbride J, Moussaoui D, Nazroo J, Qureshi A, Stompe T, Tribe R. WPA guidance on mental health and mental health care in migrants. 
World Psychiatry. 2011 Feb;10(1):2-10. doi: 10.1002/j.2051-5545.2011.tb00002.x. PMID: 21379345 ; PMCID: PMC3048516.

12. Cantor-Graae E, Selten JP. Schizophrenia and migration: a meta-analysis and review. Am J Psychiatry. 2005 Jan;162(1):12-24. doi: 10.1176/appi.ajp.162.1.12. PMID: 15625195

13. Семке В.Я. Экологическая психиатрия: настоящее и будущее. Социальная и клиническая психиатрия. 1992. Т. 2, вып. 3. С. 19-22. Semke VYa. Environmental Psychiatry: Present and Future. Social and Clinical Psychiatry. 1992;2(3):19-22 (in Russian).

14. Семке В.Я., Положий Б.С. Пограничные состояния и психическое здоровье. Томск : Изд-во Том. ун-та, 1990. 208 с. Semke VYa, Polozhy BS. Borderline states and mental health. Tomsk: Publishing House of Tomsk University, 1990:208 (in Russian).

15. Аврамова Е., Логинов Д. Социальные ресурсы адаптации населения (количественные оценки). Мониторинг общественного мнения: экономические и социальные перемены. 2002. № 3. C. 13-17. Avramova E, Loginov D. Social resources of adaptation of the population (quantitative estimates). Monitoring Public Opinion: Economic and Social Changes. 2002;3:13-17 (in Russian).

16. Тхостов А.Ш., Арина Г.А. Теоретические проблемы исследования внутренней картины болезни. Психологическая диагностика отношения к болезни при нервно-психической и соматической патологии. Л., 1990. С. 32-38. Tkhostov ASh, Arina GA. Theoretical problems of studying the internal picture of the disease. Psychological diagnostics of attitudes towards illness in neuropsychiatric and somatic pathology. Leningrad, 1990:32-38 (in Russian).

17. Беляева Л. Социальная стратификация и средний класс в России. М. : Изд-во Академия, 2001. 183 c. Belyaeva L. Social stratification and the middle class in Russia. Moscow: Publishing House Akademia, 2001:183 (in Russian).

18. Арина Г.А. Психосоматический симптом как феномен культуры. Телесность человека: междисциплинарные исследования. М., 1991. С. 4554. Arina GA. Psychosomatic symptom as a cultural phenomenon. Human sense of body: crossdisciplinary research. Moscow, 1991:45-54 (in Russian).
19. Fergusson DM, Horwood LJ, Lynskey MT. Prevalence and comorbidity of DSM-III-R diagnoses in a birth cohort of 15 year olds. J Am Acad Child Adolesc Psychiatry. 1993 Nov;32(6):1127-34. doi: 10.1097/00004583-199311000-00004. PMID: 8282656.

20. Johnson JV, Hall EM. Job strain, work place social support, and cardiovascular disease: a crosssectional study of a random sample of the Swedish working population. Am J Public Health. 1988;78(10):1336-1342. doi:10.2105/ajph.78.10.

21. Jacobson D. Models of stress and meanings of unemployment: reactions to job loss among technical professionals. Soc Sci Med. 1987;24(1):13-21. doi: 10.1016/0277-9536(87)90134-1. PMID: 3823993.

22. Rowlands P, Huws R. Psychological effects of colliery closures. Int J Soc Psychiatry. 1995 Spring; 41(1):21-5. doi: 10.1177/002076409504100102. PMID: 7622337

23. Yelin E, Mathias SD, Buesching DP, Rowland C, Calucin RQ, Fifer S. The impact on unemployment of an intervention to increase recognition of previously untreated anxiety among primary care physicians. Soc Sci Med. 1996 Apr;42(7):1069-75. doi: 10.1016/0277-9536(95)00297-9. PMID: 8730912.

24. Ликвидировать разрыв в течение жизни одного поколения : соблюдение принципа справедливости в здравоохранении путем воздействия на социальные детерминанты здоровья : заключительный доклад. Женева: ВО3, 2009. 244 с. Bridging the Generation Gap: Respect for Equity in Health Care by Addressing the Social Determinants of Health: Final Report. Geneva: World Health Organization, 2009:244 (in Russian).

25. Wahlbeck K, Cresswell-Smith J, Haaramo P, Parkkonen J. Interventions to mitigate the effects of poverty and inequality on mental health. Soc Psychiatry Psychiatr Epidemiol. 2017 May;52(5):505514. doi: 10.1007/s00127-017-1370-4. Epub 2017 Mar 9. PMID: 28280872.

26. Давыдова Н.М., Седова Н.Н. Материальноимущественные характеристики и качество жизни богатых и бедных. Социологические исследования. 2004. № 3 (239). C. 40-50. Davydova NM, Sedova NN. Material and property characteristics and quality of life of rich and poor. Sociological Research. 2004;3(239):40-50 (in Russian).

Поступила в редакцию 3.03.2021 Утверждена к печати 28.05.2021

Артемьев Игорь Андреевич, д.м.н., ведущий научный сотрудник отделения аддиктивных состояний. SPINкод РИНЦ 4752-8978. AuthorID РИНЦ 262592. AuthorID Scopus 56560293700. ORCID iD 0000-0002-4856-1590. ResearcherID J-3131-2017.

\section{Артемьев Игорь Андреевич, igor.artemev.39@mail.ru}


UDC 616.89+167/168-022.3:616.89.008.441.13:613.83:330.564.2

For citation: Artemiev I.A. Continuity as a scientific and conceptual futurological approach to the epistemology of social psychiatry. Siberian Herald of Psychiatry and Addiction Psychiatry. 2021; 2 (111): 73-81. https://doi.org/10.26617/1810-3111-2021-2(111)-73-81

\title{
Continuity as a scientific and conceptual futurological approach to the epistemology of social psychiatry
}

\section{Artemiev I.A.}

Mental Health Research Institute, Tomsk National Research Medical Center, Russian Academy of Sciences Aleutskaya Street 4, 634014, Tomsk, Russian Federation

\begin{abstract}
The article examines the exploratory strategic directions that have formed over the past two decades as part of the development of a multilevel continuity in the study of social determinants of mental health of separate social groups and society as a whole. Such universal and potentially significant indicators were chosen as the main ones, which have a brutal effect on the full range of social development of the entire population, regardless of territorial (regional, local, etc.) location, ethnic and cultural characteristics, material well-being and social status of the population, and also other external and internal factors influencing directly and indirectly. We studied the relationship of the main socio-demographic parameters that are common for the entire population of the region under consideration, such as population migration, unemployment and the prevalence of mental disorders, the correlation of poverty indicators and money incomes of the population with the level of registered alcoholism and drug addiction in the region.
\end{abstract}

Keywords: social psychiatry, nosological and syndromological direction, sociometric methods, mental health care, alcoholism, migration, unemployment, poverty.

Received March 3.2021

Accepted May 28.2021

Artemyev Igor A., MD, lead researcher of the Department of Addictive States, Mental Health Research Institute, Tomsk National Research Medical Center, Russian Academy of Sciences, Tomsk, Russian Federation. SPIN-code 4752-8978. AuthorID Russian Science Citation Index 262592. AuthorID Scopus 56560293700. ORCID iD 00000002-4856-1590. ResearcherID J-3131-2017.

Artemyev Igor A., igor.artemev.39@mail.ru 